\title{
CRECHES NAS UNIVERSIDADES FEDERAIS: QUESTÕES, DILEMAS E PERSPECTIVAS
}

\author{
Marilena Dandolini RaupP
}

RESUMO: Este artigo se propõe a apresentar novos desafios para as unidades universitárias federais de educação infantil, principalmente a partir da Constituição Federal de 1988, que indica para essas unidades um papel institucional além do que é definido para a educação infantil pública. Esses desafios indicam para a maioria delas a necessidade de assumirem, além do ensino, outras funçōes: a pesquisa e a extensão. Com base nessa análise, o artigo aponta para a necessidade de as unidades repensarem questôes polêmicas ainda presentes, direcionando essas questões para a realização de um projeto institucional com definições claras do papel das unidades de educação infantil no interior da universidade.

Palavras-chave: Creches universitárias. Infância na universidade. Educação infantil. Creches. Pré-escolas.

\section{DAYCARE CENTERS WITHIN FEDERAL UNIVERSITIES: QUESTIONS, DILEMMAS AND PERSPECTIVES}

ABSTRACT: This paper intends to present new challenges to the federal university units of children's education, with special regards to the Federal Constitution of 1988 that established an institutional role to those units that goes beyond what is defined for children's public education. In most of these units, such challenges lead to other functions besides teaching: research and extension. Taking this into consideration, this paper points out these units have to reflect upon the controversial issues still in discussion, and direct the discussions towards the development of an institutional project that clearly defines the roles of these children's units of education within universities.

Key words: Daycare centers in universities. Childhood in the university. Children's education. Daycare centers. Preschools.

\footnotetext{
* Mestre em Educação, professora do Núcleo de Desenvolvimento Infantil da Universidade Federal de Santa Catarina (UFSC) e integrante do Núcleo de Estudos da Educação de 0 a 6 anos da mesma Instituição.E-mail: mariraupp@bol.com.br
}

Educ. Soc., Campinas, vol. 25, n. 86, p. 197-217, abril 2004 
Creches nas universidades federais: questōes, dilemas e perspectivas

\section{Introdução}

A

$s$ unidades de educação infantil nas universidades federais emergem como objeto desta investigação a partir do debate instalado em fóruns de discussão ${ }^{1}$ da área que levantaram questionamentos a respeito das creches nas universidades. Esses debates incidem diretamente sobre aquilo que diz respeito ao papel dessas unidades no interior da universidade.

Dessa forma, o objetivo deste trabalho é buscar dados que dêem visibilidade às características das unidades de educação infantil nas universidades federais e compreender o papel que essas unidades vêm realizando.

Direciono a investigação inicialmente para uma caracterização ampla do conjunto dessas unidades identificadas em universidades federais e focalizo o estudo em três unidades que assumem funções que vão além da educação das crianças, nas quais os seus profissionais estão articulados com a formação, a pesquisa e a prestação de serviços à comunidade, elementos indispensáveis na constituição de uma instituição de ensino superior, compromisso social que deve ser perseguido principalmente pelas instituiçóes públicas. Assim sendo, busco referências construídas em consonância com o ideal de uma universidade democrática e alimentadora do debate entre diferentes perspectivas. Acredito que a legitimidade da universidade se baseia na idéia de instituição social, inseparável da idéia de democracia e de democratização do saber como forma de garantir uma especificidade, que é o bem mais precioso da universidade: "Ser uma instituição social constituída por diferenças internas que correspondem às diferenças dos seus objetos de trabalho, cada qual com uma lógica própria de docência e de pesquisa" (Chaui, 2001, p. 125).

\section{Encaminhamentos metodológicos}

A partir dos debates locais e nacionais em fóruns de discussão da área da educação infantil que remetem à discussão do papel das creches na universidade, as seguintes questôes foram sendo identificadas e delimitaram o campo de análise: a) a função atual da creche universitária é assistencial ou acadêmica?22; b) que espaço devem 
ocupar as creches nas universidades?3; e c) qual a função das creches na universidade após a Lei de Diretrizes e Bases da Educação Nacional de $1996 ?^{4}$

Considerando o conhecimento restrito sobre a temática, busco responder também a outras questôes com o intuito de qualificar os horizontes de análise do objeto de estudo: d) quantas unidades de educação infantil são mantidas nas Instituições Federais de Ensino Superior (IFES)?; e) quais os períodos de criação?; f) surgiram como integrantes do programa acadêmico?; como benefício dos trabalhadores das IFES?; como atendimento a necessidades sociais?; como um direito da criança?; g) quais programas mantêm?; e h) como se caracterizam os programas?

Para a compreensão da problemática, optei por um estudo ancorado em reflexôes teóricas informadas pela revisão bibliográfica, em dados empíricos obtidos com questionários e em entrevistas com profissionais de três das instituições.

Deparei-me com dificuldades para encontrar conhecimento acumulado sobre creche universitária e, pela escassez de referências, procurei alargar o levantamento bibliográfico nesse campo de conhecimento. Em uma tentativa de ir além da restrita produção brasileira, busquei, inclusive, inteirar-me de experiências norte-americanas sobre o tema, que tratam dos Centros de Cuidados da Criança no Campus, nos Estados Unidos (Barbour \& Bersani, 1991), uma coletânea (Katz et al., 1991) que possibilita o diálogo com outros trabalhos. As demais contribuições nacionais sobre o tema vieram principalmente de Ronchi Filho (1995) e Fagundes (1997), que tratam de creches universitárias.

Para a compreensão histórica da creche, foram relevantes os trabalhos de Oliveira (1988), Oliveira et al. (1989, 1992), Rosemberg (1989a, 1989b, 1992), Haddad (1990) e Campos et al. (1993), que se referem às questões de luta por creches a partir dos movimentos sociais da década de 1970 e às conquistas da creche como um direito da mulher e do trabalhador, hoje vista, principalmente, como um direito da criança.

No que se refere às funções atuais da educação infantil, as referências foram Rocha (1999), Cerisara (1999) e Faria (1999), que reafirmam objetivos pedagógicos próprios e que consideram as dimen- 
Creches nas universidades federais: questōes, dilemas e perspectivas

sões contextuais das relações estabelecidas nos espaços de convívio das instituições de educação infantil.

As contribuiçōes quanto às funções da universidade foram obtidas nos trabalhos de Saviani (1984), Fávero (2000), Sguissardi (2000) e Chaui (1999, 2001), que defendem a legitimidade da universidade inseparável da idéia de democracia e de democratização do saber.

Os questionários compuseram-se de um conjunto de indicadores cujo objetivo foi estabelecer a caracterização de aspectos sobre a organização dos serviços dessas unidades de educação infantil. Enviei-os para todas as unidades de educação infantil das universidades federais, tendo obtido o retorno de $88 \%$ de questionários respondidos. Os indicadores estão tabulados em uma base de dados tratados com estatística descritiva de cruzamentos entre variáveis e apresentados com ilustrações, quadros e tabelas. A análise é interpretativa para o exame dos dados qualitativos, observando-se as regularidades, que, segundo Azanha (1992), não significam repetição de fatos, mas semelhanças.

A partir da revisão bibliográfica e de questionários, compus um roteiro de entrevistas realizadas em três núcleos de educação infantil de distintos estados. O critério para a escolha desses três núcleos foi baseado no interesse em qualificar o quadro analítico a partir do que estou chamando de as funçôes que vão além da educação das crianças. $\mathrm{O}$ uso dessa expressão caracteriza o trabalho daquelas instituições que sistematicamente desenvolvem atividades de ensino, pesquisa e extensão. Somam-se 8 entrevistados em cada universidade, perfazendo um total de 24 entrevistas, sendo 4 professores de cada núcleo de educação infantil e outros 4 que atuam em departamentos de ensino da universidade, seguindo o critério de maior envolvimento na trajetória dos núcleos pesquisados, definido pela participação na elaboração de documentos, projetos e participação no processo de formação em serviço de profissionais do núcleo.

Um começo da história: creche na universidade... creche no local de trabalho

Tratar de educação infantil nas universidades remete à abordagem do percurso de luta por creches, intenso na década de 1970, 
processo desencadeado pelos movimentos sociais e liderado pelas mulheres trabalhadoras, feministas, empregadas de empresas públicas e privadas, e pelos sindicatos, que reivindicavam o atendimento à criança na faixa etária de 0 a 6 anos, como também pela abordagem da educação compensatória pautada na teoria da privação cultural, ${ }^{5}$ que, apesar dos seus malefícios, teve na expansão dos serviços seu maior benefício.

Por isso, como parte do esforço por desvelar o papel que as creches universitárias federais vêm realizando, destaca-se essa década, em que também foi criada a Creche Francesca Zácaro, mais precisamente em 1972, na Universidade Federal do Rio Grande do Sul, identificada como a primeira creche de universidade federal, um período marcado pelo acirramento profundo das contradições na sociedade brasileira em conseqüência do advento da ditadura militar.

Segundo Haddad (1990), a década de 1970 caracterizou-se pela eclosão de vários movimentos sociais, e, em alguns lugares, a creche representou forte apelo, passando a ser reivindicada como um direito das mulheres trabalhadoras (p. 30-31). Essa reivindicação da mulher trabalhadora decorreu do aumento da sua inserção no mercado de trabalho, a partir de transformaçōes na sociedade, como a expansão industrial, o crescimento das cidades e as modificações na organização e estrutura da família contemporânea, uma luta determinada por razões concretas, ou seja, pela necessidade de ter um local onde pudessem deixar seus filhos para aumentar a renda familiar por meio do trabalho remunerado.

Também nesse período de luta pela creche era evocado o Decreto-Lei $n^{\circ} 5.452$, existente desde 1/5/1943, que aprovou a Consolidação das Leis do Trabalho (CLT). No referido decreto-lei estão inclusos artigos que tratam sobre salas de amamentação no local de trabalho.

Outras leis também vigoravam nesse período em que os movimentos sociais e as lutas feministas reivindicavam creche para a mulher trabalhadora: a Portaria no 1, de 15/1/1969 (Bobbio, 1969, p. 117), e a Portaria no 1 de 6/1/1971 (Bobbio, 1971, p. 119), baixadas pelo Departamento Nacional de Segurança e Higiene do Trabalho/DNSHT.

Porém, cabe ressaltar que essas legislações, de acordo com Fagundes (1997), 
Creches nas universidades federais: questōes, dilemas e perspectivas

Não tratam de direito à creche nos locais de trabalho, mas somente do direito da mulher trabalhadora de amamentar seu filho durante a jornada de trabalho. Ainda assim é um direito apenas da mulher, mas restrito, pois não são todas as mulheres que têm esse direito, mas aquelas que têm idade entre 16 e 40 anos e trabalham em empresas cujo número de funcionárias contratadas atinge o mínimo estipulado pela lei (30 mulheres), e somente as que amamentam. Em relação às crianças, as restrições são: somente para crianças amamentadas e até os seis meses de idade (p. 77).

Foi nesse contexto de reivindicações dos movimentos sociais com a vigência de dispositivos legais que as creches passaram a ser uma luta de comunidades universitárias como um direito de assistência à criança na ausência da mãe, um período, segundo Rosemberg (1989a), caracterizado pela multiplicação de novas formas de luta por creche: "É a organização de empregados de empresas públicas e privadas que levanta dados sobre necessidades, elabora projetos, avalia custos, forma comissões e obtém, junto à direção, a instalação de creches" (p. 97).

Nesse processo, a esfera governamental federal, nas universidades federais, foi criando creches em suas estruturas. De 52 Instituições Federais de Ensino Superior (IFEs) 19 delas instalaram 26 creches. ${ }^{6}$ É um número que diz muito sobre a situação, pois, de um universo de 52 IFES, 33 não mantêm unidade de educação infantil. Esses dados sugerem que a existência das unidades de educação infantil nas IFES está relacionada à existência dos centros urbanos, confirmando o que revelam Oliveira \& Ferreira (1989):

O histórico da reivindicação por creches tem demonstrado que, nos grandes centros urbanos brasileiros, onde movimentos populares são mais atuantes como mecanismos de pressão política, aquela reivindicação tem se intensificado nos últimos anos e adquirido conotaçóes novas, saindo da postura do paternalismo estatal ou empresarial e exigindo a creche como direito do trabalhador. (p. 32)

Outro dado a ser observado é que, se por um lado existem 33 IFES que não mantêm unidades de educação infantil, por outro, há IFES que mantêm mais de uma. Esse fato decorre da necessidade de atendimento da demanda, uma vez que foram criadas na perspectiva de serem creches no local de trabalho.

Após a inauguração, em 1972, da primeira creche em universidade federal, reivindicações da comunidade universitária levaram 
à inauguração de mais quatro unidades na década de 1970, totalizando cinco unidades em funcionamento.

É na década de 1980 até 1992 que as creches nas universidades federais têm sua grande expansão com a inauguração de 15 novas unidades. A ampliação do número de unidades teve influência dos avanços da educação infantil e do crescimento da área como campo de pesquisa, que, a partir dos meados da década de 1980, passa por significativas transformações, principalmente a partir da Constituição Federal de 1988, quando a creche passa a ser reivindicada também como um direito das crianças - até então havia sido principalmente a reivindicação de um direito da mulher trabalhadora.

O aumento no número de creches na década de 1980 é tratado por Oliveira et al. (1992) ao referirem-se às negociações trabalhistas que aumentaram o número de creches mantidas por empresas industriais e comerciais e por órgãos públicos para os filhos de seus funcionários. $\mathrm{O}$ atendimento por elas prestado busca superar a função de substituição da família e propõe garantir o desenvolvimento cognitivo, emocional e social das crianças.

É nessa época também que os servidores da universidade federal, tanto mulheres quanto homens, passam a ter o direito à creche no local de trabalho. Esse direito é obtido em 1986, a partir de um dispositivo legal, Decreto ${ }^{\circ}$ 93.408, de 10/10/1986, ${ }^{7}$ que dispóe sobre a instituição de planos de assistência pré-escolar para os filhos de servidores de órgãos e entidades da Administração Federal direta e indireta e de fundações sob supervisão ministerial.

A partir desse dispositivo legal, a creche no local de trabalho, que até então era um direito apenas da mulher trabalhadora com idade entre 16 e 40 anos, com filhos em período de amamentação, passa a ser um direito trabalhista para os filhos de servidores de órgãos e entidades da Administração Federal e das fundações.

Nas universidades federais, esse dispositivo legal favoreceu a expansão do número de unidades de educação infantil no interior das próprias universidades, contudo sem possibilidades de atendimento à demanda total das crianças na faixa etária de 0 a 6 anos, filhos de seus trabalhadores. Esse fato é constatado tanto a partir dos dados dos questionários, que revelam critérios de seleção para ingresso das crianças, como pela existência de unidades alternativas de educação in- 
Creches nas universidades federais: questōes, dilemas e perspectivas

fantil em universidades federais, que estão incluídas no mapeamento realizado nesta pesquisa. Essas unidades alternativas se caracterizam pela manutenção de associações de pais, fundações universitárias ou municipais, associações de funcionários da universidade. São mantidas com financiamento próprio e algumas também contam com funcionários da universidade.

As creches nas universidades federais iniciam-se com o objetivo básico de atender filhos da comunidade universitária. Duas delas ampliam o atendimento para a comunidade em geral. Três unidades, além de atender filhos da comunidade universitária, incluem outros objetivos, o que dá oportunidade ao campo de estágio, de pesquisa e de observação para o âmbito universitário.

Aqui, fica evidenciado o fato de que as unidades de educação infantil nas universidades federais tiveram seus objetivos iniciais relacionados ao atendimento de necessidades trabalhistas, na medida em que a população atendida era formada, principalmente, por filhos de servidores públicos federais e também de alunos das universidades.

No âmbito das discussões sobre a Constituição Federal de 1988, foi analisada a necessidade da obtenção de garantia de creches e pré-escolas nos locais de trabalho:

A importância de se conquistar esse serviço para as crianças de 0 a 6 anos é indiscutível (Teles; Medrado; Gragnani, 1986), como também é inegável o avanço político dessa luta que, de um lado, passa a considerar, mais recentemente, o direito dos filhos de funcionárias e dos funcionários, evitando a restrição da oferta de emprego às mulheres, e que, de outro lado, defende o papel educativo do atendimento às crianças de 0 a 6 anos e não apenas o de guarda, por considerá-las como cidadãs. (Kramer, 1989, p. 52)

Nesses termos, o Grupo de Trabalho da Educação Pré-Escolar da ANPED propôs que fosse incluído no capítulo II da Constituição Federal, referente aos direitos sociais, do Título II (Os direitos e as liberdades fundamentais), a garantia de educação e assistência, pelo empregador, aos filhos e dependentes dos empregados, pelo menos até 6 anos de idade, em creches e pré-escolas, nas empresas privadas e em órgãos públicos. Essa indicação significava, naquele período, possibilidade de ampliação de vagas, numa fase caracterizada por uma necessidade de maior expansão de creches e pré-escolas nos serviços públicos. 
Não obstante o esforço de professores, pesquisadores e militantes, a Constituição Federal de 1988 não instituiu como direito dos servidores públicos civis e militares a assistência gratuita aos filhos e dependentes desde o nascimento até 6 anos. Campos et al. (1993, p. 23) consideraram a questão afirmando que seria viável prever que leis complementares preencheriam a lacuna da ausência do direito a creche no local de trabalho, na Constituição Federal.

Em dezembro de 1993, o Decreto no 977, de 10/11/93, baixado pela Secretaria da Administração Federal da Presidência da República, disciplina a assistência pré-escolar destinada aos dependentes dos servidores públicos da Administração Pública Federal direta, autárquica e fundacional. Caracteriza-se num dispositivo legal que surge na contramão da expansão das unidades de educação infantil nesses órgãos federais. Institui o auxílio pré-escolar ${ }^{8}$ como assistência indireta aos servidores para proporcionar atendimento aos dependentes, na faixa etária de 0 a 6 anos, em creches e pré-escolas, mantém as unidades integrantes da estrutura do órgão ou da entidade federal existentes, pró́be a criação de novas unidades a partir da data desse dispositivo e mantém os contratos ou convênios até o prazo final com instituições particulares ou com entidades públicas, vedando a prorrogação desses contratos/convênios.

Mesmo assim, três novas unidades são criadas. Provavelmente, foram criadas a partir de um processo em andamento, como podemos perceber nos motivos que levaram à criação da Creche da Universidade Federal Fluminense, em outubro de 1997:

Nasceu após 10 anos de luta em resposta ao sonho e à luta de alguns professores que abraçaram a idéia de construir um estabelecimento que oferecesse um atendimento de alta qualidade às crianças de zero a seis anos além de constituir-se num campo de investigação e prática que possibilitasse a formação profissional e acadêmica dos estudantes de graduação e pós-graduação interessados na instância da Educação Infantil. ${ }^{9}$

Medidas legais criadas a partir da Constituição Federal de 1988 intensificam os debates sobre o papel das creches universitárias federais, na medida em que direcionam o direito à educação infantil como sendo de todas as crianças, sejam elas filhas de trabalhadores ou não, e o direito de creches e pré-escolas aos filhos de 
Creches nas universidades federais: questōes, dilemas e perspectivas

trabalhadores, sejam eles do serviço público ou não, na medida em que incluem a educação infantil na educação básica, direcionam para o município a manutenção de creches e pré-escolas e instituem o auxílio pré-escolar aos trabalhadores públicos federais em substituição à creche no local de trabalho.

Os avanços referentes à educação infantil obtidos com a legislação, destacando-se no presente quadro a Constituição Federal de 1988 e a Lei de Diretrizes e Bases da Educação Nacional de 1996, como também a valorização da criança nos contextos sociais contemporâneos, levaram ao fortalecimento da área da educação infantil. Pesquisadores como Shiroma, Moraes \& Evangelista (2000) avaliam que essa área se transformou numa das habilitações mais demandadas nos cursos de pedagogia e uma fértil e promissora linha de pesquisa.

Esses fatos indicam que as universidades, diante da demanda por cursos de pedagogia com habilitação na área da educação infantil, são pressionadas por necessidades tais como campos de estágio e observaçōes na área em unidades de educação de crianças na faixa etária de 0 a 6 anos.

Por sua vez, essas necessidades direcionam as creches nas universidades a ampliarem suas funções para o âmbito da formação dos acadêmicos que atuarão nessa área. Esse conjunto de fatos relacionados às creches nas universidades impulsiona a maioria delas, no decorrer de suas trajetórias, à revisão de suas funções, direcionandoas para atuar além da educação das crianças, impelindo-as a explorar outras possibilidades, tais como campo de estágio, campo de pesquisa e de observação.

Diante desse panorama, percebe-se que os determinantes da expansão das creches nas universidades federais se originam em motivaçōes exteriores às necessidades das crianças de 0 a 6 anos e, mais do que isso, exteriores à própria proposta da universidade. Além disso, a proximidade com a vida universitária acaba por agregar desafios importantes à reflexão sobre as crianças. A resposta que algumas poucas unidades têm conseguido dar na direção de uma prática que alie ensino, pesquisa e extensão parece ser uma luz a iluminar o debate sobre a pertinência dessas unidades de educação infantil no âmbito universitário.

Educ. Soc., Campinas, vol. 25, n. 86, p. 197-217, abril 2004 
As unidades de educação infantil no âmbito universitário

Ao examinar o quadro referente à situação de vinculação das diferentes unidades de educação infantil pesquisadas, encontrei uma situação, no mínimo, curiosa. Apenas quatro unidades de educação infantil têm vinculação com centros de educação na universidade. As demais unidades possuem vinculação com órgãos variados: pró-reitorias, recursos humanos, órgão estudantil, hospital, assistência social, fundação, assuntos comunitários, Departamento de Economia Doméstica, entre outros. O fato de $83 \%$ dessas unidades estarem vinculadas a outros órgãos universitários que não da educação contradiz um tanto a importância do vínculo com a área da educação, destacada por alguns autores. Essa situação significa, por um lado, a predominância da vinculação associada aos objetivos iniciais das unidades; por outro, a necessidade de amadurecer a importância da presença dessas unidades para o desenvolvimento de um campo de pesquisa novo.

No que se refere aos objetivos atuais, a maioria das unidades de educação infantil caracteriza-se como campo de estágio para cursos da universidade. Praticamente todas as unidades são também campo de pesquisa e de observações, ou seja, dispõem sua estrutura de funcionamento a profissionais das múltiplas áreas de conhecimento da universidade para coleta de dados para pesquisa ou para observações.

Estudos realizados sobre a presença dos Centros de Cuidados da Criança no Campus, de autores norte-americanos, também revelam a contribuição que esses centros podem oferecer no âmbito da formação dos acadêmicos da universidade:

Os Centros de Cuidados da Criança no Campus têm potencial para se transformarem em escolas de desenvolvimento de profissionais para a universidade. É a consolidação de um espaço que serve não apenas para demonstrar práticas, mas também para unir os professores de salas de aula e os alunos da universidade em uma parceria que poderá afetar o desenvolvimento da educação, tanto para as crianças de hoje quanto para os professores de amanhã. (Barbour \& Bersani, 1991, p. 45-46)

No caso brasileiro, múltiplas são as áreas que buscam as unidades de educação infantil como campo de estágio e de desenvolvimento de profissionais. Para além da pedagogia, também as áreas de psi- 
Creches nas universidades federais: questōes, dilemas e perspectivas

cologia, educação física, enfermagem, odontologia, nutrição, música, belas-artes, desenho industrial, fonoaudiologia, letras, jornalismo, agronomia, economia doméstica, fisioterapia, farmácia, serviço social, medicina, artes plásticas, teatro e dança demonstram o grande interesse que a educação das crianças pequenas vem despertando.

Muitos são os dilemas na atuação das unidades referente à formação acadêmica. $\mathrm{O}$ fato é que a maioria dos entrevistados caracteriza os estágios nas unidades de educação infantil nas universidades federais como uma referência de formação acadêmica distante da realidade da maioria das instituições públicas de educação infantil. Tais considerações recaem principalmente sobre a população atendida pela maioria das unidades, que é restrita à comunidade universitária.

A proposta de revisão da população atendida na maioria das unidades, com a ampliação para a comunidade em geral, passa pela necessidade de a prática pedagógica revelar questões que emergem de contextos socioculturais amplos, refletindo, dessa forma, uma questão central da área da educação infantil, que é a necessidade de se conhecerem melhor as crianças. Essa mudança visa ao fortalecimento das unidades como campo de formação profissional tanto no âmbito dos estágios quanto servindo como campo de observaçôes e pesquisas e na produção e socialização de conhecimentos.

No âmbito da graduação e da pós-graduação da universidade, a procura das unidades de educação infantil das universidades federais para desenvolvimento de pesquisas inclui pedagogia, psicologia, educação física, nutrição, odontologia, medicina, engenharia de produção, arquitetura, enfermagem, fisioterapia, farmácia, economia doméstica e educação artística. Essa multiplicidade de áreas que procuram as unidades de educação infantil no interior da universidade revela que tais unidades se caracterizam como uma referência que parece oferecer contribuição no processo de formação acadêmica também como campo de pesquisa, além de campo de estágio. Autores como Sebastiani (1996), por exemplo, consideram que ser campo de pesquisa constitui um fator de qualidade da área da educação infantil:

A creche, por ser uma instituição relativamente recente, ainda necessita de informações e de aprofundamento. Mas podemos dizer que é uma instituição que produz cultura e que se constitui em um campo privilegiado de pesquisa para estudiosos das ciências sociais e, em especial, do desenvolvimento 
infantil. É essa inter-relação das ciências que permite o enriquecimento e a melhoria dos serviços, uma vez que é capaz de fornecer instrumentos de análise e pontos de referência para a inovação e a avaliação das estruturas e da organização dos trabalhos da creche. (p. 70)

Os dados levantados apontam também que as unidades que desenvolvem os objetivos de pesquisa e de extensão (produção e socialização de conhecimentos) totalizam apenas $13 \%$ do conjunto estudado. A construção dos objetivos de produção e socialização de conhecimentos dá-se em consonância com o princípio norteador das atividades da universidade: indissociabilidade entre ensino, pesquisa e extensão. O reconhecimento desse princípio é assumido num entendimento mais amplo sobre o papel de uma unidade de educação infantil universitária federal dentro da lógica de funcionamento do universo acadêmico, no qual a pesquisa se apresenta como fio condutor de todas as açôes, sustentando as demais atividades desenvolvidas pela unidade.

Nesse percurso de busca de consolidação da identidade acadêmica, destaca-se o perfil de formação dos professores dessas unidades, que ainda requerem maior qualificação com vistas ao desenvolvimento da complexidade das atividades de ensino, pesquisa e extensão.

Essa busca por melhor qualificação dos professores tem sido considerada uma componente fundamental para responder ao questionamento do que justificaria a presença das unidades de educação infantil no interior das universidades.

Assim como os campos de estágios, observações e pesquisas são permeados de reflexões que indicam redefinições, o campo da produção de conhecimentos também segue essa direção. A produção de conhecimentos nessas unidades requer reflexóes que direcionem para a ampliação dessa frente de atuação como também para a busca de um caráter de pesquisa institucional, ou seja, que investiguem problemáticas que emerjam da prática pedagógica institucional. Logo, tem-se considerado pouco o que seja o saber oriundo de questóes vividas diretamente com as crianças nas unidades.

A configuração exposta revela que a constituição das unidades de educação infantil nas universidades federais, de alguma forma, acompanha a trajetória histórica da educação infantil no Brasil no que se refere aos objetivos iniciais, cumprindo a função de atendimento 
Creches nas universidades federais: questōes, dilemas e perspectivas

às crianças pequenas enquanto suas mães trabalhavam e estudavam. Evoluiu, gradativamente, no decorrer dos anos, para a incorporação de novas funçôes, caracterizadas como campo de estágio, de pesquisa e de observação. No entanto, essas funções necessitam de ampliação para a prática da pesquisa e da extensão, condição imprescindível para a consolidação da identidade universitária dessas unidades.

Considerações finais: recompondo os olhares

Os dados permitiram fazer uma caracterização dessas unidades quanto a aspectos que revelam os seus programas institucionais. A partir desse conhecimento básico sobre uma determinada realidade, tornou-se possível descobrir quais são as questóes que, prioritariamente, precisam ser repensadas e modificadas, de forma que se abra espaço para o envolvimento dos profissionais em discussões e definiçôes de propostas à construção da identidade acadêmica das unidades de educação infantil nas universidades federais. Se existem diversas questões que precisam ser repensadas, são também os avanços construídos com essas mesmas questões que permitirão uma análise mais complexa e ampla em futuras investigações.

De uma forma sintética, concluímos que as questões a seguir apresentadas precisariam ser priorizadas quando fossem rediscutidos os programas institucionais dessas unidades.

As unidades como campo de formação profissional e como área referente à educação não podem prescindir de uma inter-relação com professores dos departamentos de ensino da área da educação, compreendida como essencial a fim de se estabelecer um contato direto com o conhecimento produzido e sistematizado. Essa relação constante permite a reflexão da prática pedagógica das unidades, o que amplia o campo de atuação no âmbito dos estágios, da pesquisa e da extensão.

A consolidação da identidade acadêmica de unidades fica prejudicada na medida em que características dos programas institucionais refletem limitações do que significa uma unidade pública de educação infantil no seu sentido pleno, como a restrição da população atendida à comunidade universitária, a limitação do período de atendimento às crianças e o atendimento de somente parte da faixa 
etária de 0 a 6 anos. Numa perspectiva de educação infantil pública plena, as reflexóes atuais demandam a ampliação no perfil da clientela da maioria dessas unidades, assim como a redefinição do período de atendimento às crianças e a inclusão de atendimento do ciclo completo da educação infantil: 0 a 6 anos, possibilitando novas contribuições nos campos de estágio, observações, pesquisa, produção e socialização do conhecimento na área da educação de crianças nessa faixa etária.

O que se percebe é que servir como campo de estágio, de observações e de pesquisa não é condição exclusiva da unidade de educação infantil da universidade, uma vez que essas funçôes podem ser viabilizadas, em condiçôes diferenciadas, nas demais redes de educação infantil. O estágio na unidade de educação infantil da universidade que busca a consolidação de sua identidade acadêmica pode ocorrer numa prática pautada pela produção do conhecimento da unidade, com profissionais disponíveis para a interlocução, uma vez que o estágio é da natureza da unidade. Mesmo assim, a unidade de educação infantil da universidade caracteriza-se como uma referência, entre outras, para servir como campo dessas funçôes à comunidade universitária.

Quanto ao perfil dos profissionais que trabalham com as crianças, há que se pensar que, na maioria dos casos, essa formação foi realizada num tempo e num espaço em que ainda não estava em construção a perspectiva de uma pedagogia da educação infantil. A construção dessa pedagogia própria para a área se caracteriza na busca da especificidade do trabalho a ser realizado com crianças na faixa etária de 0 a 6 anos. Significa a superação do caráter escolar ainda presente nas instituições de educação infantil. Trata-se de novos tempos, que indicam outro perfil de profissional para atuar na educação infantil, portanto sendo necessária essa revisão no âmbito da formação do conjunto de profissionais que atuam nas unidades.

A atuação como campo de estágio requer uma revisão de concepção, fazendo dele, de acordo com Ostetto (2000), "um momento de encontro entre educadores em formação e educadores que já estão atuando na educação infantil e que, no processo, experimentam uma verdadeira formação em serviço" (p. 15). O processo de estágio envolve a construção de atitudes dos educadores: diálogo, interlocução,

Educ. Soc., Campinas, vol. 25, n. 86, p. 197-217, abril 2004 
Creches nas universidades federais: questões, dilemas e perspectivas

troca, que direcionam para a construção coletiva do conhecimento como sendo uma via de mão dupla em que ambos os lados aprendem. Isso significa a superação da visão da unidade de educação infantil na universidade como "modelo" pelo simples fato de estar no âmbito universitário.

No desenvolvimento da pesquisa, produção de conhecimentos, há de se buscar a necessidade da criação de uma cultura científica para a maioria das unidades e sua ampliação para outras unidades, indo além das pesquisas em função de monografias, dissertações e teses para titulação dos docentes. É necessário garantir também a pesquisa institucional, coletiva, que investigue questôes que emergem da prática pedagógica nas unidades.

No campo da extensão, socialização de conhecimentos, deve-se promover uma aproximação, principalmente com a rede pública, caracterizando esse campo de atuação como um espaço de troca e interlocução, de construção de relaçôes baseadas no respeito à especificidade de cada instituição, o que se constitui numa efetiva alternativa para a qualificação do trabalho desenvolvido com crianças de 0 a 6 anos. Essa visão se articula com alguns temas hoje colocados em debate no âmbito da formação de professores para a educação infantil: a qualidade do atendimento, como um direito da criança pequena, e a contribuição da universidade na formação dos professores.

Enfim, é necessário que sejam definidos princípios para as unidades consolidarem uma identidade universitária, assunto a ser discutido a partir de articulações internas, entre os profissionais das unidades, destes com profissionais dos órgãos universitários, em especial com professores de centros de educação, e externas, em fóruns de discussão da área, redes de educação infantil, com movimentos sociais organizados e sindicatos.

Considerando que a universidade tem como objetivo formar pesquisadores e profissionais para o mercado de trabalho que sirvam à sociedade, ela tem nas unidades de educação infantil mais um lugar onde se pode dar subsídios teóricos e práticos, um lugar que possibilita uma articulação teórica e prática do que seria o trabalho de educação em um determinado nível.

Logo, a razão de as unidades de educação infantil existirem é para poder fazer um trabalho de um nível de educação infantil que 
busque responder a demandas e desafios colocados para a educação infantil pública, caracterizando-se, além de campo para educação de crianças, como espaço de formação acadêmica e profissional, que produz e socializa conhecimentos.

No entanto, se considerarmos o contexto do conjunto das unidades de educação infantil nas universidades federais, os desafios para que essas unidades contribuam para a excelência acadêmica das universidades, integrando os princípios norteadores de uma política de educação superior desejada para nosso país, são tantos e ainda maiores. Mesmo assim, esses desafios não serão diferentes de outros desafios pelos quais sempre valeu a pena lutar.

\section{Recebido em fevereiro de 2003 e aprovado em novembro de 2003.}

\section{Notas}

1. I Encontro Nacional de Coordenadores de Creches Universitárias, outubro de 1987, Florianópolis; Seminário Financiamento de Políticas Públicas para Crianças de 0 a 6 Anos, outubro de 1987, São Paulo; II Simpósio Nacional de Educação Infantil e IV Simpósio Latino-Americano de Atenção Integral à Criança, novembro de 1996, Brasília; Seminário Internacional da Organização Mundial da Educação Pré-Escolar/omep, julho de 2000, Rio de Janeiro; I Seminário de Creches em Universidades Paulistas: as Creches Públicas nas Universidades Paulistas - em busca de um significado, setembro de 2000, São Paulo.

2. Discussão central do I Encontro Nacional de Coordenadores de Creches Universitárias (NDI/UFSC/1987).

3. Questão que integrou os debates no Seminário Financiamento de Políticas Públicas para Crianças de 0 a 6 Anos (Campos et al., 1987).

4. Temática do I Seminário de Creches em Universidades Paulistas (COSEAS/Usp/2000).

5. A teoria da privação cultural, invocada no Brasil e no exterior, considerava o atendimento à criança pequena em creches uma possibilidade de superação das condições sociais precárias a que a criança estava sujeita, por meio de uma educação compensatória, sem a alteração das estruturas sociais existentes na raiz daqueles problemas.

6. Unidades de educação infantil neste estudo são aquelas que desenvolvem a educação de crianças na faixa etária de 0 a 6 anos na modalidade creche ou pré-escola, portanto não fazendo parte desta investigação outras modalidades como brinquedotecas, CAICs/Centros de Atenção Integral à Criança e ao Adolescente, turmas de educação infantil em colégios de aplicação, escolinhas de esportes etc.

7. Essa legislação estabelece que tais órgãos, entidades e fundações viabilizem o atendimento às crianças de 0 a 6 anos, filhos dos servidores, por meio de creches, instituiçôes materno-infantis e jardins-de-infância integrantes de sua própria estrutura organizacional ou que contratem, mediante licitação, os serviços de instituições particulares, ou ainda que utili-

Educ. Soc., Campinas, vol. 25, n. 86, p. 197-217, abril 2004

Disponível em <http://www.cedes.unicamp.br> 
Creches nas universidades federais: questōes, dilemas e perspectivas

zem, mediante convênios, as instituições de atendimento à criança de 0 a 6 anos conjuntamente com outros órgãos ou entidades públicos (Cardoso, 1986).

8. O auxílio pré-escolar é uma assistência financeira recebida mensalmente pelo servidor público da Administração Pública Federal direta, autárquica e fundacional que tem filhos na faixa etária de 0 a 6 anos, o que significa um benefício que visa a substituir a creche no local de trabalho.

9. Dado obtido em documento entregue na reunião de creches universitárias que ocorreu no Seminário Internacional da Organização Mundial da Educação Pré-Escolar, em julho de 2000, no Rio de Janeiro.

\section{Referências bibliográficas}

AZANHA, J.M.P. Uma idéia de pesquisa educacional. São Paulo: EDUsP, 1992.

BARBOUR, N.B.; BERSANI, C.U. The Campus Child Care Center as a professional development school. Early Childhood Research Quarterly, Norwood, v. 6, n. 1, p. 43-49, Mar. 1991.

BRASIL. Constituição (1988). Constituição da República Federativa do Brasil. Brasília, DF: Senado, 1988.

BRASIL. Lei no 9.394/96, de 20 de dezembro de 1996. Estabelece as diretrizes e bases da educação nacional. Diário Oficial da União. Brasília, DF, 23 dez. 1996. p. 27894.

BOBBIO, P.V. (Org.). LEX: coletânea de legislação federal e marginália. São Paulo: Lex, 1969.

BOBBIO, P.V. (Org.). LEX: coletânea de legislação federal e marginália. São Paulo: Lex, 1971.

BOBBIO, P.V. (Org.). LEX: coletânea de legislação federal e marginália. São Paulo: Lex, 1993.

CAMPOS, M.M.; ROSEMBERG, F.; FERREIRA, I.M. Creches e préescolas no Brasil. São Paulo: Cortez, 1993.

CARDOSO, C.M. Boletim de Direito Educacional, Belo Horizonte, v. 11, n. 10, p. 6-7, out. 1986.

CERISARA, A.B. Educar e cuidar: por onde anda a educação infantil? In: Cerisara, A.B. (Org). Educação infantil: temas e debates. Perspectiva, Florianópolis, v. 17, n. 32, p. 11-21, jul./dez. 1999. 
CHAUI, M. Universidade operacional: a atual reforma do Estado incorpora a lógica do mercado e ameaça a instituição universitária. Folha de S. Paulo, 9 maio 1999. Caderno Mais!

CHAUI, M. Escritos sobre a universidade. São Paulo: UNESP, 2001.

FAGUNDES, M.R. A creche no trabalho... o trabalho na creche: um estudo sobre o Centro de Convivência Infantil da Unicamp: trajetória e perspectivas. 1997. 179f. Dissertação (Mestrado em Educação) - Faculdade de Educação, Universidade Estadual de Campinas, Campinas.

FARIA, A.L.G. O espaço físico como um dos elementos fundamentais para a pedagogia da educação infantil. In: FARIA, A.L.G.; Palhares, M.S. (Org.). Educação infantil pós- $L D B$ : rumos e desafios. Campinas: Autores Associados; São Carlos: UfSCAR, 1999. p. 6797.

FÁVERO, M.L.A. (Org.). Universidade do Brasil: das origens à construção. Rio de Janeiro: UFRJ; INEP, 2000.

HADDAD, L. A creche em busca de identidade: perspectivas e conflitos na construção de um projeto educativo. São Paulo: Loyola, 1990 .

KATZ, L.G.; WALSH, D.J.; GOINS, B. (Org.). Early Childhood Research Quarterly, Norwood, v. 6, n. 1, march 1991.

KRAMER, S. Política de financiamento para creches e pré-escolas: razões políticas e razões práticas. In: CAmpos, M.M.; FARIA, A.G. (Org.). Financiamento de políticas públicas para crianças de 0 a 6 anos. Cadernos ANPED, n. 1, p. 43-56, 1989.

OLIVEIRA, Z.M.R. A creche no Brasil: mapeamento de uma trajetória. Revista Faculdade de Educação, São Paulo, v. 14, n. 1, p. 43-52, jan./jun. 1988.

OLIVEIRA, Z.M.R.; FERREIRA, M.C.R. Propostas para o atendimento em creches no Município de São Paulo: histórico de uma realidade - 1986. In: RosemberG, F. (Org.). Temas em destaque: creche. São Paulo: Cortez; Fundação Carlos Chagas, 1989. p. 28-89. 
Creches nas universidades federais: questōes, dilemas e perspectivas

OLIVEIRA, Z.M.R.; MELLO, A.M.; VITÓRIA, T.; FERREIRA, M.C.R. Creches: crianças, faz-de-conta \& cia. Petrópolis: Vozes, 1992.

OSTETTO, L.E. Andando por creches e pré-escolas públicas: construindo uma proposta de estágio. In: Ostetto, L.E. (Org.). Encontros e encantamentos na educação infantil. Campinas: Papirus, 2000. p. $15-30$.

ROCHA, E.A.C. A pesquisa em educação infantil no Brasil: trajetória recente e perspectiva de consolidação de uma pedagogia da educação infantil. 1999. Tese (Doutorado) - Universidade Federal de Santa Catarina, Florianópolis.

RONCHI FILHO, J. A pré-escola Criarte da UFES: sua trajetória e seus conflitos na tentativa de construção de um projeto pedagógico: um estudo de caso. 1995. Dissertação (Mestrado em Educação) - Universidade Federal do Espírito Santo, Vitória.

ROSEMBERG, F. O movimento de mulheres e a abertura política no Brasil: o caso da creche - 1984. In: Rosemberg, F. (Org.). Temas em destaque: creche. São Paulo: Cortez; Fundação Carlos Chagas, 1989a. p. 90-102.

ROSEMBERG, F. A educação da criança pequena, a produção do conhecimento e a universidade. In: Campos, M.M.; Faria, A.G. (Org.). Financiamento de políticas públicas para crianças de 0 a 6 anos. Cadernos ANPED, n. 1, p. 57-64, 1989 b.

ROSEMBERG, F. A educação pré-escolar brasileira durante os governos militares. Cadernos de Pesquisa, São Paulo, n. 82, p. 21-30, 1992.

SAVIANI, D. Ensino público e algumas falas sobre universidade. São Paulo: Cortez: Autores Associados, 1984.

SEBASTIANI, M.T. Educação infantil: o desafio da qualidade; um estudo da rede municipal de creches em Curitiba. 1996. Tese (Doutorado em Educação) - Faculdade de Educação, Universidade Estadual de Campinas, Campinas. 
SGUISSARDI, V. O desafio da educação superior no Brasil: quais as perspectivas? In: SGUisSARd, V. (Org.). Educação superior: velhos e novos desafios. São Paulo: Xamã, 2000. p. 8-46.

SHIROMA, E.O.; MORAES, M.C.M.; EVANGELISTA, O. O que você precisa saber sobre... politica educacional. Rio de Janeiro: DP\&A, 2000 .

TELES, M.A.A.; MEDRADO, M.A.; GRAGNANI, A.M.C. Creches e berçários em empresas privadas paulistas. In: RosemberG, F. (Org.). Temas em destaque: creche. São Paulo: Cortez; Fundação Carlos Chagas, 1989. p. 104-134. 